\title{
EXPERIMENTAL STUDIES ON A POWDER-SNOW AVALANCHE
}

\author{
by
}

\author{
K. Kawada,
}

(Faculty of Science, Toyama University, 3190 Gofuku, Toyama 930, Japan)

\author{
K. Nishimura, and N. Maeno
}

(Institute of Low Temperature Science, Hokkaido University, Sapporo 060, Japan)

\section{ABSTRACT}

To make clear the structure and behaviour of a large-scale avalanche, the impact force-data obtained in the avalanche project of 1972-78 were analysed in detail. The wave forms of impact forces are classified into two types. Type 1 is composed of many separate spikes each of which represents the collision of a snow block. Type 2 has wider peaks, caused by collisons of snow blocks mixed with fluidized snow. Most of the type 1 peaks were in the width range corresponding to $0.005-0.01 \mathrm{~s}$ duration, and most type 2 peaks fell into the $0.02-0.1 \mathrm{~s}$ range.

The internal velocities of an avalanche were estimated by calculating cross-correlation spectra for a time series of impact-force records. It was discovered that these internal velocities varied from 10 to $50 \mathrm{~m} / \mathrm{s}$ over time. The mean distance between snow blocks was found to be in the range $1.6-5.4 \mathrm{~m}$ in a type 1 avalanche, and between 0.7 and $3 \mathrm{~m}$ in type 2 avalanches. Sizes of snow blocks or snow clouds of type 1 and type 2 were in ranges $0.26-0.52$ and $0.37-1.9 \mathrm{~m}$, respectively.

This paper also reports on the project created to initiate artificial powder-snow avalanches in the Shiai-dani area and to make systematic observations of a variety of physical aspects. Results obtained in 1988 for both artificial and natural avalanches are given.

\section{INTRODUCTION}

Abnormal amounts of snowfall on a steep slope often generate large-scale avalanches, which may cause great damage to various constructions and buildings and also to human beings. The Kurobe Canyon in the North Japan Alps has been known as a district of frequent large-scale powder-snow occurrences (Fig. 1). These avalanches have been named $\mathrm{Hou}$ in the Kurobe dialect, and are assumed to be huge high-speed avalanches of dry snow with a powder component. A typical disaster, in which 84 workmen were killed, was the avalanche that occurred on 27 December 1938 in the Shiai-dani, one of tributaries of the Kurobe Canyon. It fell on a sturdy, semi-subterranean, four-storey wooden building on a cliff about $20 \mathrm{~m}$ higher than the valley bottom, in the snowy season (Fujihira, 1968).

The actual characteristics of such avalanches as these have never been investigated in detail. Ogasahara (1966, 1968) surveyed the Kurobe Canyon and reported that the $\mathrm{Hou}$ might be an avalanche of blast type. Later, in 1972-78, an extensive study was made in the Shiai-dani area by a joint group from Toyama University and Hokkaido University. Its main purpose was to discover the overall features and dynamics of this avalanche type, although detailed systematic analyses of the data obtained could not be made to clarify the characteristic internal and dynamic structure (Nakagawa, 1979; Shimizu and others, 1980).

Recently, the present authors have applied spectral analyses to the records of impact forces obtained in the experiments in 1972-78 and have obtained many new findings about the internal and dynamic structures, some of which have been given in Nishimura and others (1987) and Kawada (1988). At the same time, the authors have organized a systematic project of observations of powder-snow avalanches in the Shiai-dani area and have already obtained data for the winter of 1987-88. This paper gives some of the important results of our recent analyses of the old data as well as the new observations.

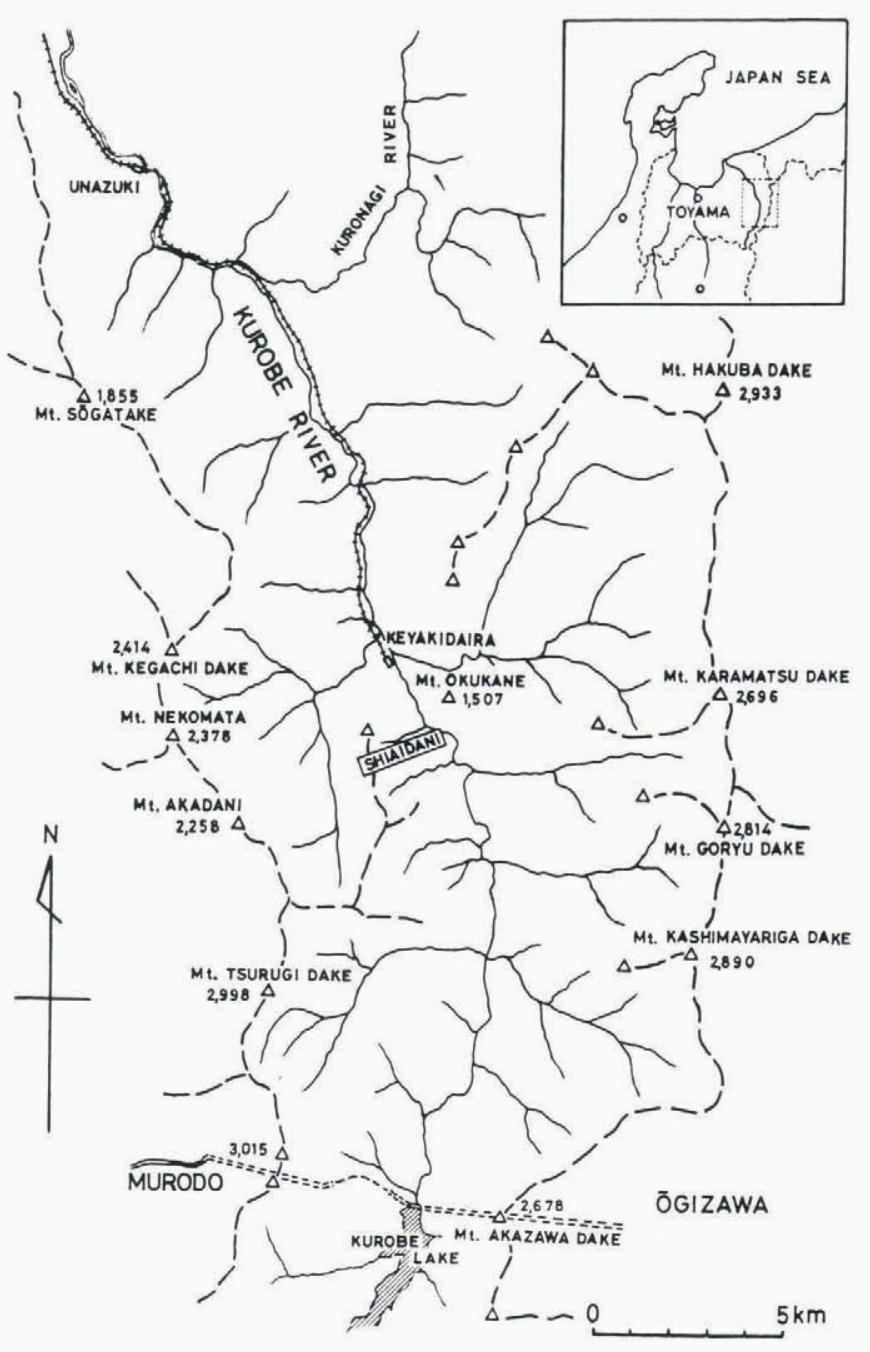

Fig. 1. Map of Kurobe Canyon. The Shiai-dani area is the observation site. 


\section{FLOW-BEHAVIOUR PATTERNS OF A LARGE- SCALE AVALANCHE REVEALED BY THE NEW ANALYSES}

\subsection{Observations $1972-78$}

The Shiai-dani, one of the tributaries of the Kurobe River, was selected as an observation site for the study of large-scale powder-snow avalanches. It originates at an elevation of $1600 \mathrm{~m}$ a.s.1., its length and mean inclination being about $2000 \mathrm{~m}$ and $33^{\circ}$, respectively. The building struck by the 1938 avalanche was on a cliff on the right bank of the Shiai-dani at an elevation of $815 \mathrm{~m}$. Its remains were selected as the observation site since they are accessible through long tunnels throughout the year and electricity is also available. The longitudinal and crosssections of the observation site are shown in Figure 2a and b.
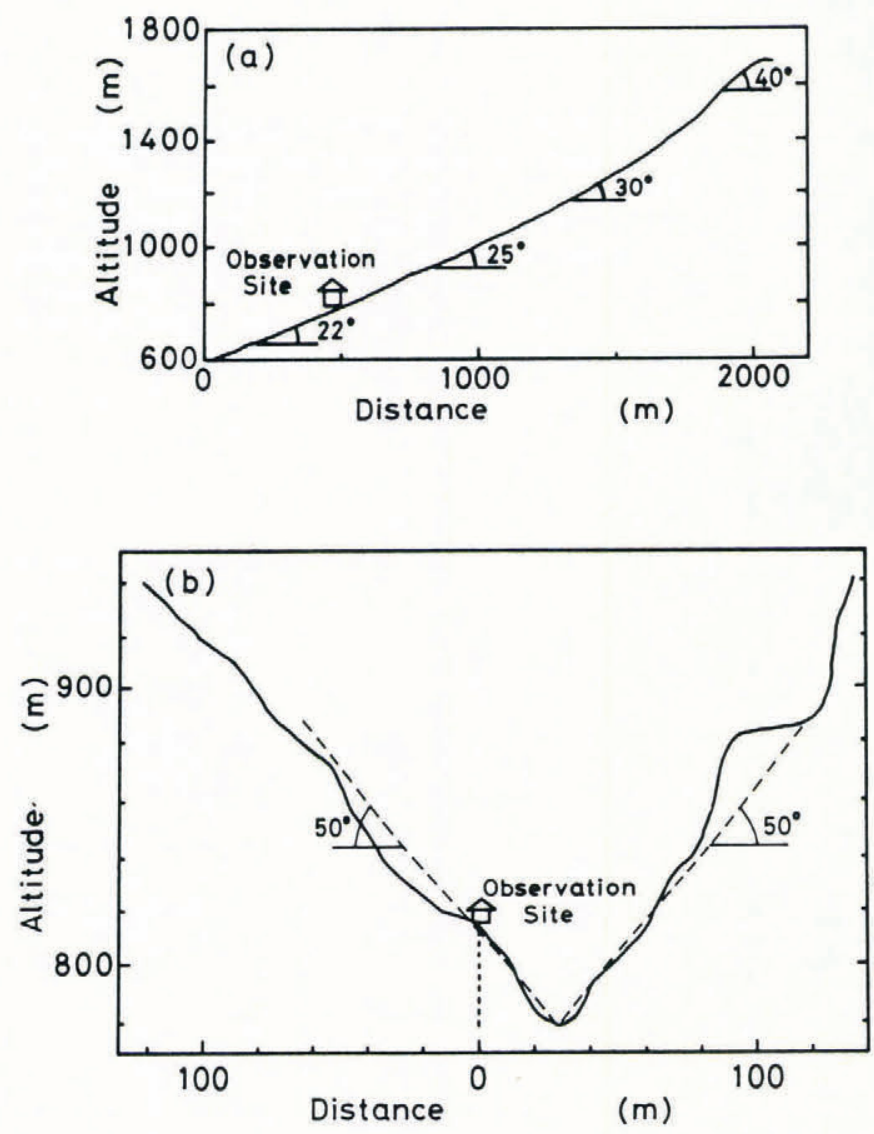

Fig. 2. Cross-sections of the observation site. (a) Along the avalanche chute. (b) Across the avalanche chute.

The climate of the Kurobe Canyon area is characterized by heavy snowfalls in winter time. Snow usually accumulates up to a depth of about $4 \mathrm{~m}$ on terraces and more than $20 \mathrm{~m}$ in depth in valleys. Air temperature varies between $-10^{\circ}$ and $+5^{\circ} \mathrm{C}$ in a cold winter season. Large-scale avalanches have a tendency to occur when the total snowfall is higher than about $400 \mathrm{~mm} / \mathrm{d}$ and the air temperature is below $0^{\circ} \mathrm{C}$.

The direction of any avalanche running through the observation site was determined from the bending of copper tubes, set on the top of pyramidal mounds installed for impact-force measurement, and of the steel poles of an anemometer. In Figure 3, arrows originating from the observation site show the orientations of bent tubes and poles after avalanches have passed. It is suggested that the avalanche running straight down in the upper region may hit the precipitous right bank in region $\mathrm{A}$ in Figure 3 and then turn sharply to the left and fall on the observation site.

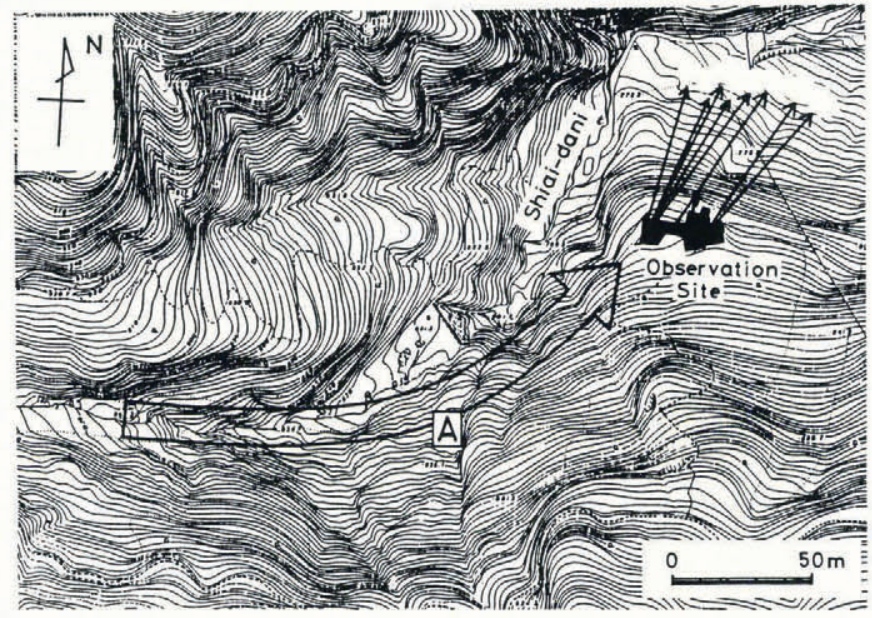

Fig. 3. Paths of large-scale avalanches passing through the observation site. The large white arrow indicates the most probable path, estimated from topographical and other considerations. Arrows originating from the observation site are paths deduced from the bending of poles.

The impact force of each avalanche was measured by using strain-gauge-type load cells attached to pressure plates $100 \mathrm{~mm}$ in diameter, and recorded by a data recorder. The pressure sensors were set at the tops of pyramidal mounds (M1 and M2) of ferro-concrete $4 \mathrm{~m}$ high, as shown in Figure 4. Signals generated by a load cell were always recorded on a rotating magnetic drum and then erased again within $0.6 \mathrm{~s}$; they were transferred to a data recorder only when an avalanche occurred. When an impact force was larger than a threshold or trigger level, the data recorder started automatically and ran for $3 \mathrm{~min}$. Since the data recorder did not reach a constant running speed until $0.3 \mathrm{~s}$ after it started, the recording was in fact begun $0.5 \mathrm{~s}$ after the trigger time. This was made possible by use of a mechanical time-delay circuit combined with the rotating magnetic drum. The trigger level of the starter was set at $125 \mathrm{kN} / \mathrm{m}^{2}$. The capacity of the load cell used was $20 \mathrm{kN}$ and the dynamic response of the system including load cells

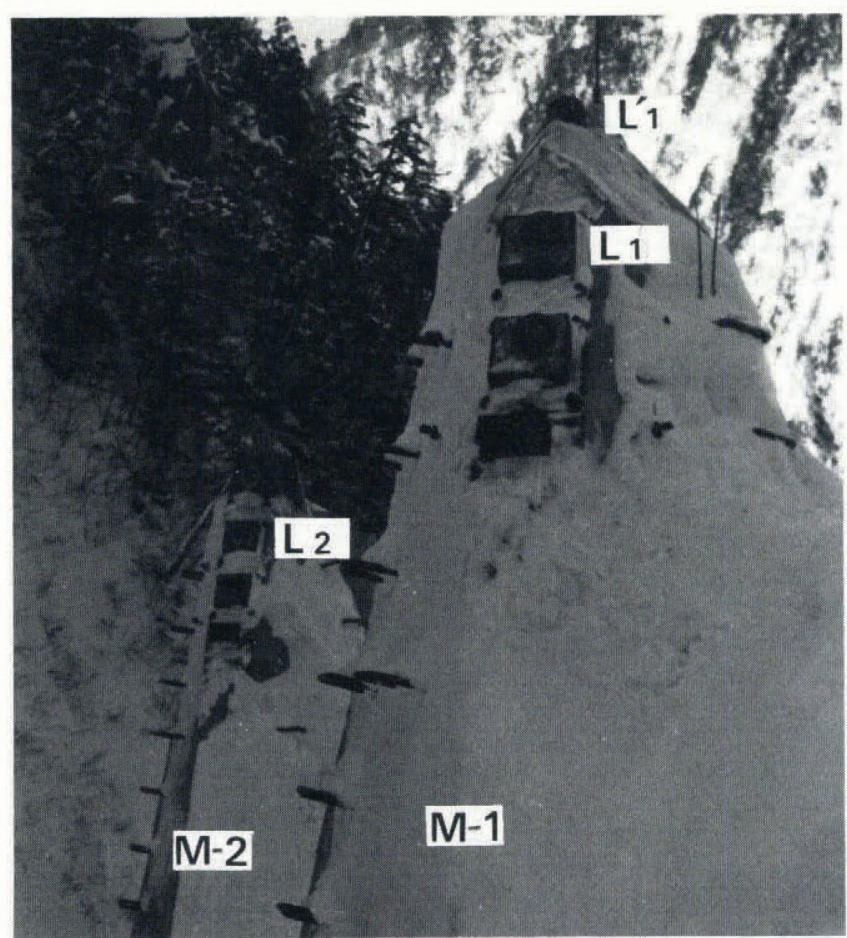

Fig. 4. Pyramidal mounds (M1, M2) constructed at the observation site in the Shiai-dani area. $\mathrm{L}_{1}, \mathrm{~L}_{1}^{\prime}$, and $\mathrm{L}_{2}$ are load cells. 
( a )

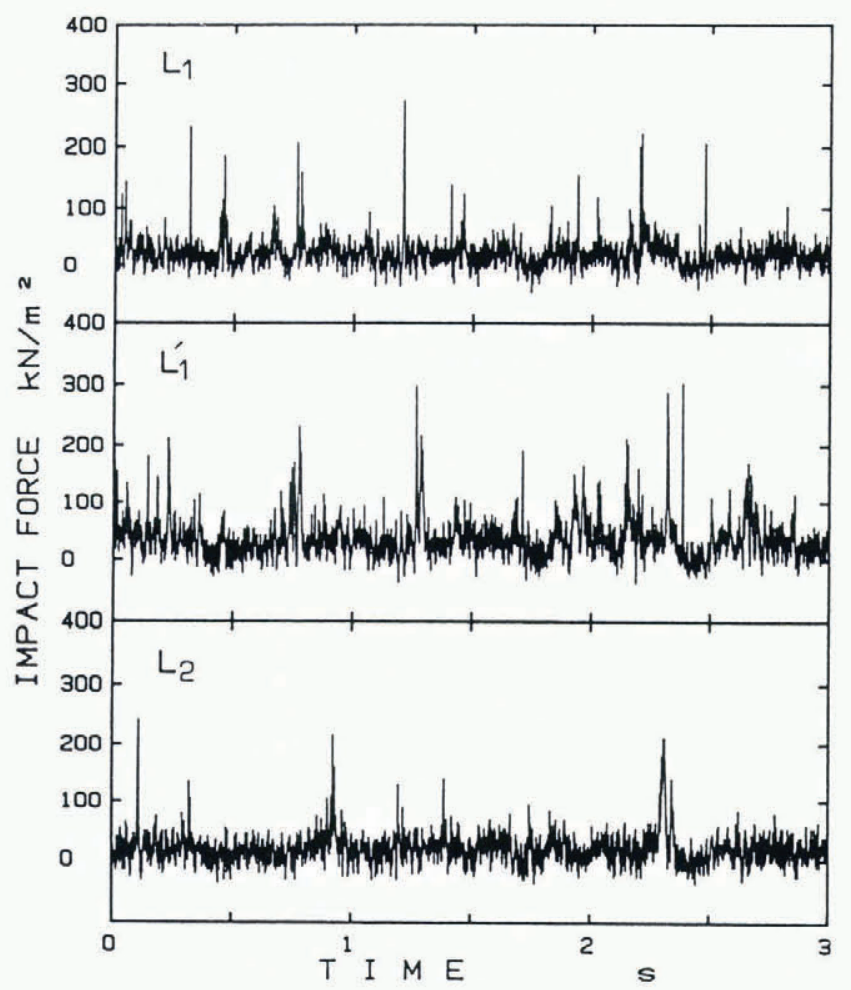

(b)

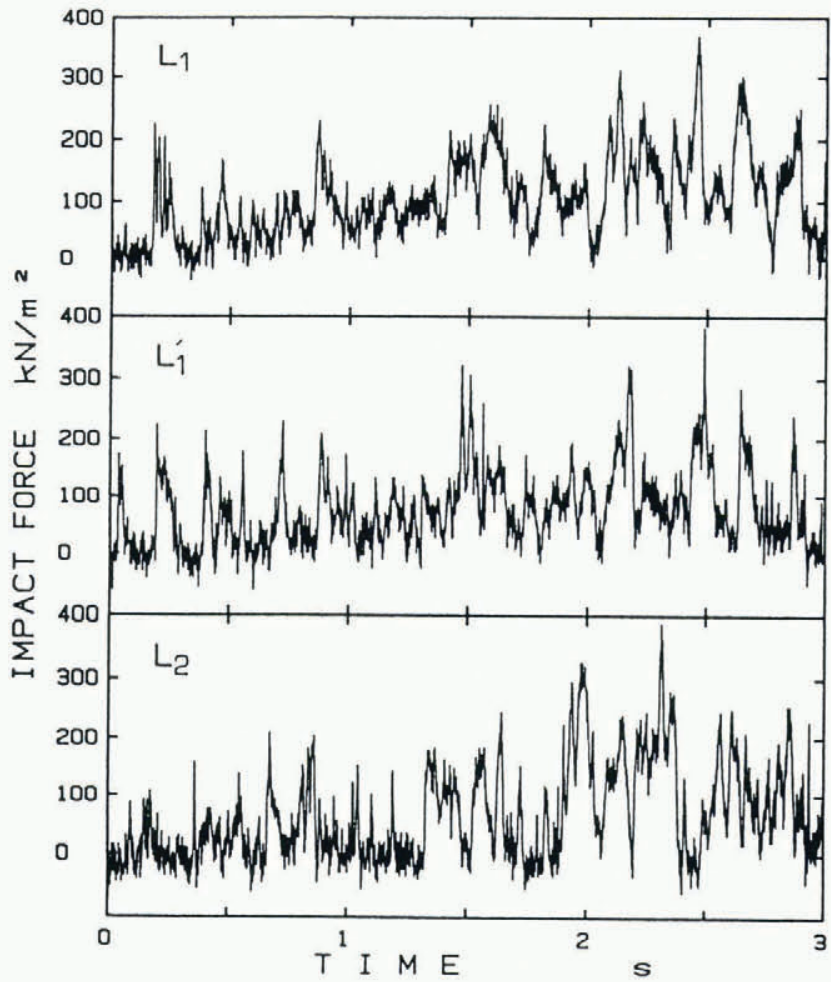

Fig. 5. Two typical records of impact force. (a) Avalanche which occurred at $07.30 \mathrm{~h}$ on $22 \mathrm{January}$

1978. (b) Avalanche which occurred at $10.58 \mathrm{~h}$ on 23 February 1978.

and pressure plates was $400 \mathrm{~Hz}$, which is sufficiently high for the accurate measurement of impact forces of avalanches.

The measurement of avalanche velocities was made from impact forces recorded at the two pyramidal mounds arranged along the dominant avalanche path (Fig. 3). The load cell $\mathrm{L}_{1}^{\prime}$ was set $450 \mathrm{~mm}$ away from the load cell $\mathrm{L}_{1}$ at the mound $\mathrm{M} 1$, and load cell $\mathrm{L}_{2}$ on the mound $\mathrm{M} 2$ was set $4.85 \mathrm{~m}$ away from load cell $\mathrm{L}_{1}$. When an avalanche hit the mounds, we calculated the avalanche velocity from the time lag of signals of impact force measured by different load cells.

\subsection{Wave forms of impact forces}

During observation in the Shiai-dani area in the 1972-78 period, a large amount of data on impact forces was obtained by using the system described above. It was found that most avalanches passing the observation site had a duration of between 3 and $12 \mathrm{~s}$; Figure $5 \mathrm{a}$ and $\mathrm{b}$ shows two sets of wave forms for the impact force. The recordings were obtained on the morning of 22 January 1978 (Fig. 5a) and 23 February 1978 (Fig. 5b), and according to Kawada (1988) the wave forms obtained have been classified as types 1 and 2 , respectively. The two types are in clear contrast; the former shows the trace appearing as a series of many individual sharp peaks, whereas the latter shows a fluctuating continuous curve composed of rather rounded peaks.

Enlarged wave forms are shown in Figure 6, in which (a) and (b) refer to type 1 waves and (c) and (d) to type 2 waves, respectively. In type 1 each of the individual pulses shows a rapid increase followed by a gradual decrease with fluctuations; each peak corresponds to the collision of one snow block. In type 2 the impact force increases and decreases relatively much more slowly than for type 1, although peaks similar to those of type 1 are sometimes contained within them. Such wave forms suggest that a type 2 avalanche is composed of relatively large snow blocks or snow clouds buried in fluidized snow.

The width of peaks is found to correspond to time intervals ranging from 0.005 to $0.01 \mathrm{~s}$ in type 1 and from 0.02 to $0.1 \mathrm{~s}$ in type 2 , and this may be used to estimate the approximate size of snow blocks and snow clouds. The number of peaks is thought to be an indication of the number of snow blocks in collision, and this number was found to vary in the range of $4-23$ blocks/s in both types of avalanche (Kawada, 1988).
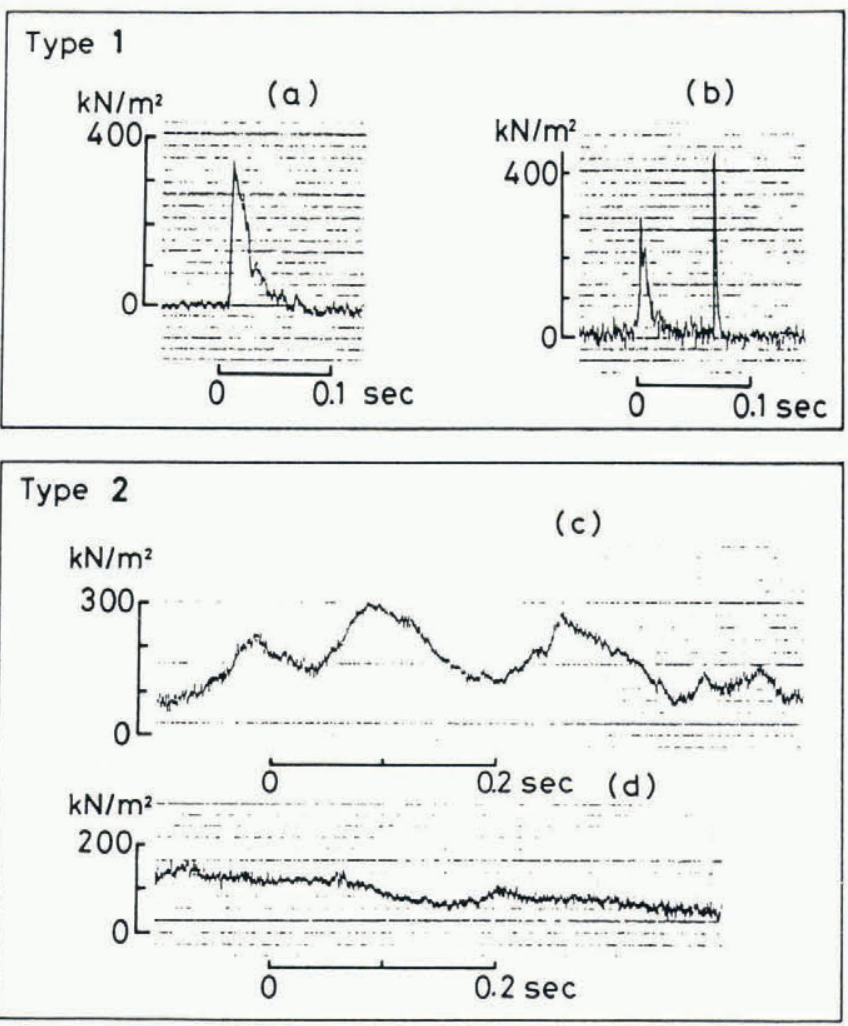

Fig. 6. Details of the wave forms of impact forces. (a) and (b) are type 1 , and (c) and (d) are type 2 . 
Knowing the velocity of an avalanche, we can estimate the mean sizes of snow blocks as well as the distances between them by use of the values for the peak number and peak width obtained and described above. Kawada (1988) obtained the following figures by using avalanche velocities estimated by the spectral analysis method given in the next section: in a type 1 avalanche the mean diameter of snow blocks is in a range $0.18-0.65 \mathrm{~m}$, and the mean distance between snow blocks ranges from 1.6 to $5.4 \mathrm{~m}$. On the other hand, in a type 2 avalanche the mean diameter and distance are in ranges $0.22-2.77 \mathrm{~m}$ and $0.7-3 \mathrm{~m}$, respectively.

\subsection{Internal velocities of avalanches}

Three load cells were installed along an avalanche path so that the mean velocity of an avalanche between them could be estimated by dividing the separation distance by the travel time. Examples of the wave forms generated by the impact forces are shown in Figure 5. In the previous analyses, visual identification of specific marks on wave patterns had been adopted as a means of obtaining avalanche velocities (Nakagawa, 1979; Shimizu and others, 1980). Such a method has never been reliable; recently the present authors have applied a high-resolution spectral technique to this analysis. First pairs of analogue-time-series data for impact force were transformed into digital values at $1 \mathrm{~ms}$ intervals with a conventional A-D converter, and then a spectral analysis with FFT algorithm was carried out for the $1 \mathrm{~s}$ interval data reading of the pairs to get a cross-correlation function. The lag time which the calculated cross-correlation function showed a maximum was considered to correspond to the difference in time between the arrival of the two waves. More details of the calculation method have been given in Nishimura and others (1987).

Figure 7 gives the time variations of internal velocities calculated at $1 \mathrm{~s}$ intervals for the two avalanches shown in Figure 5. The internal velocities show large variations with time, reflecting a complex internal structure. For the avalanche of 22 January, that is a type 1 avalanche, the
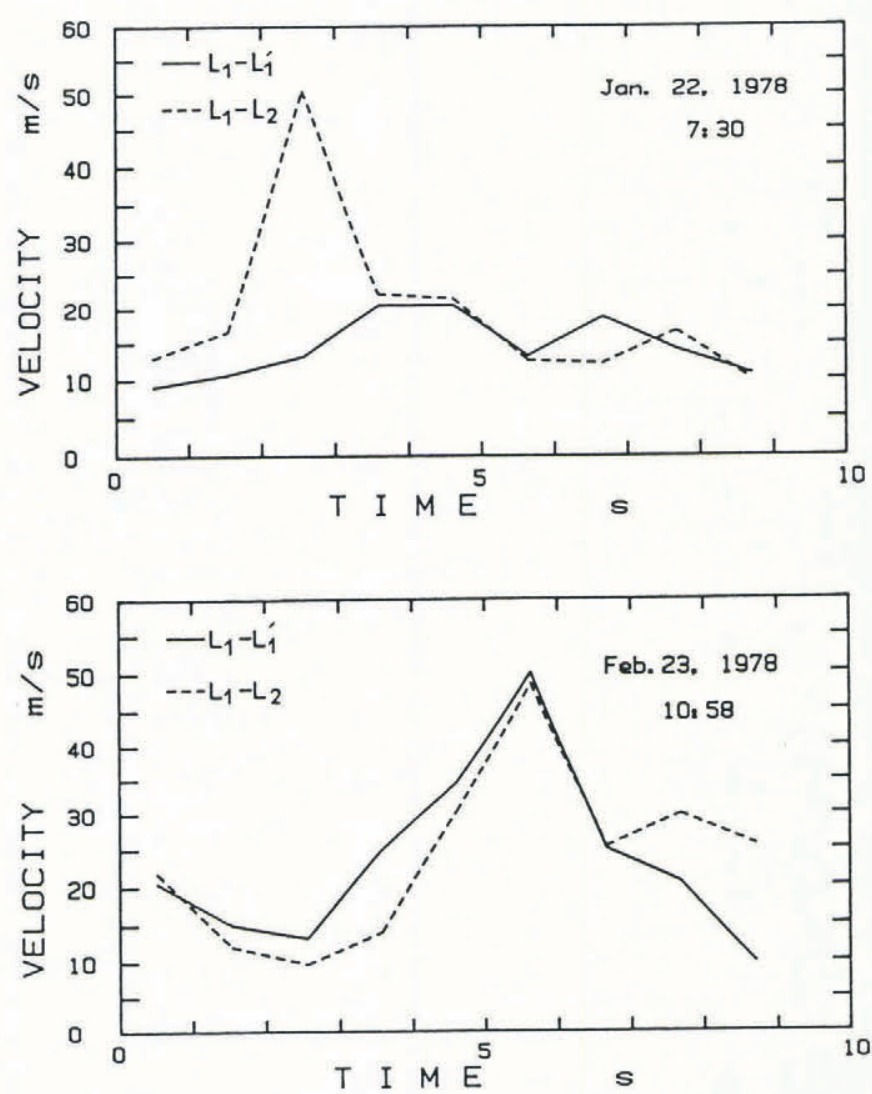

Fig. 7. Internal velocities obtained by the cross-correlation method for avalanches of 22 January and 23 February 1978 . calculation for the pair of cells $\mathrm{L}_{1}, \mathrm{~L}_{2}$ gives a large velocity amounting to $50 \mathrm{~m} / \mathrm{s}$ a few seconds after the arrival of the front, in contrast to the velocity for the cell pair $\mathrm{L}_{1}$ and $L_{1}^{\prime}$ which is roughly $10 \mathrm{~m} / \mathrm{s}$. This difference is thought to be due to the fact that the internal structure of a type avalanche is quite inhomogeneous, so that the collision behaviour of such an avalanche at $\mathrm{L}_{2}$ is very different from that at $\mathrm{L}_{1}$ and $\mathrm{L}_{1}^{\prime}$.

In contrast to this, a relatively uniform internal structure is suggested for the type 2 avalanche of 23 February (Fig. 7), both by the calculations for $L_{1} / L_{1}^{\prime}$ and for $\mathrm{L}_{1} / \mathrm{L}_{2}$. For example, the internal velocity has a value of about $20 \mathrm{~m} / \mathrm{s}$ near the avalanche front, and this value decreases to about $10 \mathrm{~m} / \mathrm{s}$ and then increases again to show a maximum near the core of the avalanche.

\section{NEW AVALANCHE EXPERIMENTS IN THE SHIAI-DANI AREA}

\subsection{Organization of the project}

A great deal of significant information relating to important structures and behaviour of the $\mathrm{Hou}$ avalanche has been obtained by extensive observations since 1972, but there still remain many unsolved problems. This may be partly because the Hou avalanche has never been directly observed. It develops only during or just after a severe snowfall when the visibility is so bad that direct observation is not possible. On the basis of this consideration, an experimental project has been discussed, and was set up in 1986 , to release artificially a large-scale powder-snow avalanche and make systematic measurements including direct visual observations. The Shiai-dani area was again chosen as the experimental site since it was considered to be the only place in Japan where such a large-scale avalanche could safely be released without causing significant ill effects and damage to the environment and to human beings.

In the project we intend to make a variety of observations on both artificial and natural avalanches. The main researchers and institutions in charge of the new project are as follows: K. Kawada (Toyama University); N. Maeno, R. Naruse, H. Narita, K. Nishimura, and G. Casassa (Hokkaido University); S. Kobayashi and K. Izumi (Niigata University); Y. Sato (Kokusai Kogyo Co., Ltd); H. Iida (Yoshida Science Museum of Kurobe City); S. Kohno (Japan Meteorology Association). The artificial triggering of an avalanche was scheduled for the end of January 1988 when heavy snowfalls are most likely and the valley will be buried in deep snow. The artificial avalanche is initiated by dynamiting large numbers of snow cornices at the ridge (1660 $\mathrm{m}$ a.s.l.). Recordings with video cameras have been made mainly from two locations; one is the midpoint (the Nozoki, at about $920 \mathrm{~m}$ a.s.1.) of the avalanche chute just above the main measurement site, and the other is the Gaki-no-Tambo on a slope just opposite the avalanche chute (at about $1650 \mathrm{~m}$ a.s.l., and roughly $4 \mathrm{~km}$ away from the main measurement site).

At the main measurement site and the midpoint of the avalanche chute, various kinds of observations were prepared for, including impact forces, temperature, air pressure, avalanche wind, and seismic activity, as well as capture of snow particles and so on. To make such measurements possible, two new $5 \mathrm{~m}$ high mounds were constructed (Fig. 8), the main part of each mound being a steel cylinder $300 \mathrm{~mm}$ in diameter on which many measuring devices were mounted. All of the data has been recorded on magnetic video tapes using two data recorders located in a room in the underground tunnel mentioned earlier in this paper.

\subsection{Results of measurements in the 1987-88 winter}

Most of the measuring devices and video cameras were set in position by the beginning of December 1987. Although the overall snowfall that year in Japan was not very large, the artificial release of a large-scale avalanche was scheduled to be made at either the end of January or the beginning of February. On the afternoon of 30 January 1988, dynamite technicians, cameramen, and researchers were transported to the ridge and Gaki-no-tambo by helicopter. Just after this transfer a heavy snowstorm began which 


\section{CONCLUDING REMARKS}

The present new analyses of the impact-force data obtained from the avalanche project in 1972-78 have produced significant information about the large-scale powder-snow avalanches which frequently occur in the Kurobe region. Such avalanches could be classified as one of two types, types 1 and 2, and estimates have been made of aspects of their internal structure such as the average size of incorporated snow blocks and the mean distance between such blocks. In addition, a large project has been set up in order to make systematic observations of large-scale powder-snow avalanches in the Shiai-dani area, some of which were released artificially and others naturally. In the first winter of this new project, 1987-88, one artificially released and several natural avalanches were observed to develop. Much of the data obtained in the avalanche project is now being analysed and will be published in the near future.

\section{ACKNOWLEDGEMENTS}

The authors would like to express their sincere thanks to the following individuals for their helpful co-operation: R. Naruse, H. Narita, G. Casassa, S. Kobayashi, K. Izumi, Y. Sato, H. Iida, and S. Kohno. They would also like to express their sincere thanks to the Kansai Electric Power Company, who supported the project and gave every support to logistic arrangements for the research operation; to the members of the Japan Broadcasting Corporation, who recorded avalanches with video cameras and gave a variety of assistance; and to many other colleagues and students who were involved in the field work. They are also indebted to local public officials; North Japan Disaster
Prevention Engineering Co.; Kokusai Kogyo Co.; and the alpine guide, I. Takashima, for helpful assistance and guidance.

\section{REFERENCES}

Fujihira, A. 1968. Shiai-dani no oo-nadare. I [Large-scale avalanche at Shiai-dani]. Toyama Shizenhogo Kyokaiho, 37. [In Japanese.]

Kawada, K. 1988. Studies on the dynamic characteristics of large-scale avalanche observed at Kurobe canyon, Japan. Contributions of Mountain Sciences, 1, 1-31.

Nakagawa, M. 1979. Kosoku nadare no hakairyoku no kenkyu [A study on the destructive force of a high-speed avalanche]. Shizen Saigai Tokubetsu Kenkyu Seika, A-53-2, 1-62. [In Japanese.]

Nishimura, K., N. Maeno, and K. Kawada. 1987. Nadare shogekiryoku no shuhasuu-kaiseki niyoru daikibo-nadare no naibu-kouzou [Internal structures of large-scale avalanches revealed by a frequency analysis of impact forces]. Low Temp. Sci., Ser. A, 46, 91-98. [In Japanese with English summary.]

Ogasahara, K. 1966. Avalanche of Kurobe gorge of the Japanese North Alps: analytical research of the frequency in occurrence of avalanche and its energy. Report of the Science Research Organization of Toyama University, 6, $1-16$.

Ogasahara, K. 1968. Kurobe kyokoku no hou nadare [Houavalanche at Kurobe canyon]. Chiri, 13(7), 62-69. [In Japanese.]

Shimizu, H., T. Huzioka, E. Akitaya, H. Narita, M. Nakagawa, and K. Kawada. 1980. A study on high-speed avalanches in the Kurobe canyon, Japan. J. Glaciol., 26(94), 141-151. 